\title{
Current perspectives on ranibizumab
}

\author{
Vaidehi S Dedania' \\ Sophie J Bakri² \\ 'Department of Ophthalmology, \\ Albany Medical Center, Lions \\ Eye Institute, Albany, NY, USA; \\ ${ }^{2}$ Department of Ophthalmology, \\ Mayo Clinic, Rochester, MN, USA
}

Correspondence: Sophie J Bakri Department of Ophthalmology, Mayo Clinic, 200 First Street SW, Rochester, MN 55905, USA

Tel + I $50728436 \mid 4$

Fax +I $50728446 / 2$

Email bakri.sophie@mayo.edu
This article was published in the following Dove Press journal:

Clinical Ophthalmology

20 March 2015

Number of times this article has been viewed

Background: This review summarizes the Phase III studies addressing intravitreal ranibizumab treatment in patients with neovascular age-related macular degeneration (AMD), macular edema (ME) from retinal vein occlusion (RVO), and diabetic ME (DME).

Results: The data from 12 major Phase III studies: six studies in patients with neovascular AMD, two studies in patients with ME from RVO, and four studies in patients with DME demonstrate significant improvement in vision in patients undergoing treatment with intravitreal ranibizumab over patients receiving no treatment or receiving only grid laser. These effects are achieved with low incidences of ocular and nonocular adverse events.

Conclusion: Intravitreal ranibizumab is a highly effective and safe therapy for improving vision and reducing vision loss in patients with neovascular AMD, ME from RVO, and DME. Patients generally require long-term treatment although some data show that frequency of treatment necessary to maintain visual outcomes decreases over time.

Keywords: age-related macular degeneration, branch retinal vein occlusion, central retinal vein occlusion, diabetic macular edema, intravitreal, macular edema

\section{Introduction}

Vascular endothelial growth factor (VEGF), a homodimeric glycoprotein, is a key regulator of physiologic and pathologic angiogenesis, and its upregulation has been shown to contribute to retinal and choroidal neovascularization $(\mathrm{CNV})$ in diseases of the posterior segment. ${ }^{1-4}$ VEGF is a critical molecule for the development of $\mathrm{CNV}$ in neovascular age-related macular degeneration (AMD) and for retinal neovascularization and macular edema (ME) in diabetic retinopathy (DR) and retinal vein occlusion (RVO). ${ }^{1-4}$ For this reason, VEGF has become the target for the treatment of these conditions, and the emergence of intravitreal VEGF inhibitors has revolutionized the management of neovascular AMD, diabetic ME (DME) and ME following central RVO (CRVO), and branch RVO (BRVO).$^{5-8}$ Ranibizumab (Lucentis; Genentech, Inc., South San Francisco, CA, USA/Roche, Basel, Switzerland) is a humanized monoclonal antibody fragment that has a high affinity for VEGF and blocks all isoforms of VEGF-A. Numerous trials (Anti-VEGF Antibody for the Treatment of Predominantly Classic Choroidal Neovascularization in AMD [ANCHOR], Minimally Classic/Occult Trial of the Anti-VEGF Antibody Ranibizumab in the Treatment of Neovascular AMD [MARINA], A Study of Ranibizumab Administered Monthly or on an As-needed Basis in Patients with Subfoveal Neovascular Agerelated Macular Degeneration [HARBOR], RhuFab V2 Ocular Treatment Combining the Use of Visudyne to Evaluate Safety [FOCUS], Branch Retinal Vein Occlusion: Evaluation of Efficacy and Safety [BRAVO], Central Retinal Vein Occlusion Study: Evaluation of Efficacy and Safety [CRUISE], Ranibizumab Injection in Subjects with Clinically Significant Macular Edema with Center Involvement Secondary to Diabetes Mellitus [RISE, NCT00473330], Ranibizumab Injection in Subjects with Clinically Significant Macular Edema with Center Involvement Secondary 
to Diabetes Mellitus [RIDE, NCT00473382]) examining the efficacy and safety of ranibizumab have showed that frequent intravitreal injections reduce the risk of vision loss in patients with $\mathrm{CNV}$ and ME. ${ }^{9-25}$

The purpose of this review is to describe the findings of major Phase III studies evaluating the efficacy and safety of intravitreal ranibizumab for the treatment of neovascular AMD, DME and ME after RVO.

\section{Efficacy}

\section{Neovascular AMD}

Intravitreal ranibizumab was US Food and Drug Administration (FDA)-approved for the treatment of neovascular AMD in 2006. MARINA ${ }^{9}$ and $\mathrm{ANCHOR}^{10,11}$ were the first two major Phase III studies that evaluated the efficacy and safety of ranibizumab in the treatment of neovascular AMD (Table 1). Results from MARINA showed that at 1 year, $94.5 \%$ and $94.6 \%$ of patients treated with ranibizumab $0.3 \mathrm{mg}$ and $0.5 \mathrm{mg}$, respectively, lost $<15$ letters compared to $62.2 \%$ of sham-treated patients $(P<0.001) .{ }^{9}$ At 2 years, $52.9 \%, 92 \%$, and $90 \%$ of patients in the sham, ranibizumab $0.3 \mathrm{mg}$, and $0.5 \mathrm{mg}$ groups, respectively, lost $<15$ letters $(P<0.001){ }^{9}$ An improvement of $\geq 15$ letters was reported in $3.8 \%, 26.1 \%$, and $33.3 \%$ of sham, ranibizumab $0.3 \mathrm{mg}$, and $0.5 \mathrm{mg}$ patients, respectively $(P<0.001) .{ }^{9}$ In ANCHOR, ${ }^{10,11}$ similar responses were seen, as ranibizumab-treated groups had significantly better visual outcomes than verteporfin photodynamic therapytreated groups $(P<0.001)$. The results of MARINA ${ }^{9}$ and $\mathrm{ANCHOR}^{10,11}$ showed that intravitreal ranibizumab treatment was superior to observation and/or verteporfin photodynamic therapy in patients with neovascular AMD. Additionally, neither MARINA ${ }^{9}$ nor ANCHOR $^{10,11}$ was designed to evaluate the superiority of one dose of ranibizumab over another, although results suggested a dose-dependent relationship. ${ }^{9-11}$ The findings in the Safety Assessment of Intravitreous Lucentis for AMD (SAILOR) ${ }^{15}$ study also suggested a dose-related response, with greater improvements in visual acuity (VA) in patients receiving ranibizumab $0.5 \mathrm{mg}$ versus $0.3 \mathrm{mg}$.

In Phase IIIb, Multicenter, Randomized, Double-masked, Sham Injection Controlled Study of the Efficacy and Safety of Ranibizumab in Subjects with Subfoveal Choroidal Neovascularization (CNV) with or without Classic CNV Secondary to Age-related Macular Degeneration (PIER), ${ }^{12,13}$ patients treated with ranibizumab had significantly better visual outcomes than patients receiving sham injection $(P<0.0001)$. Additionally, vision improved after patients were switched

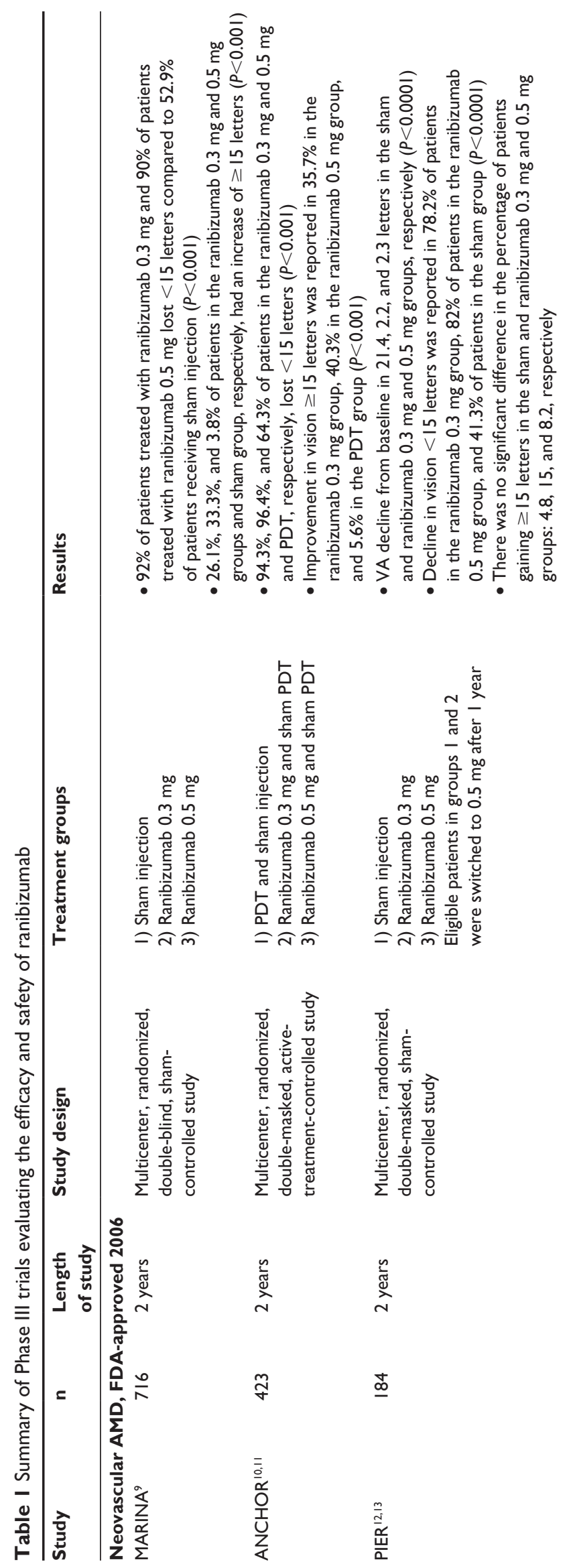



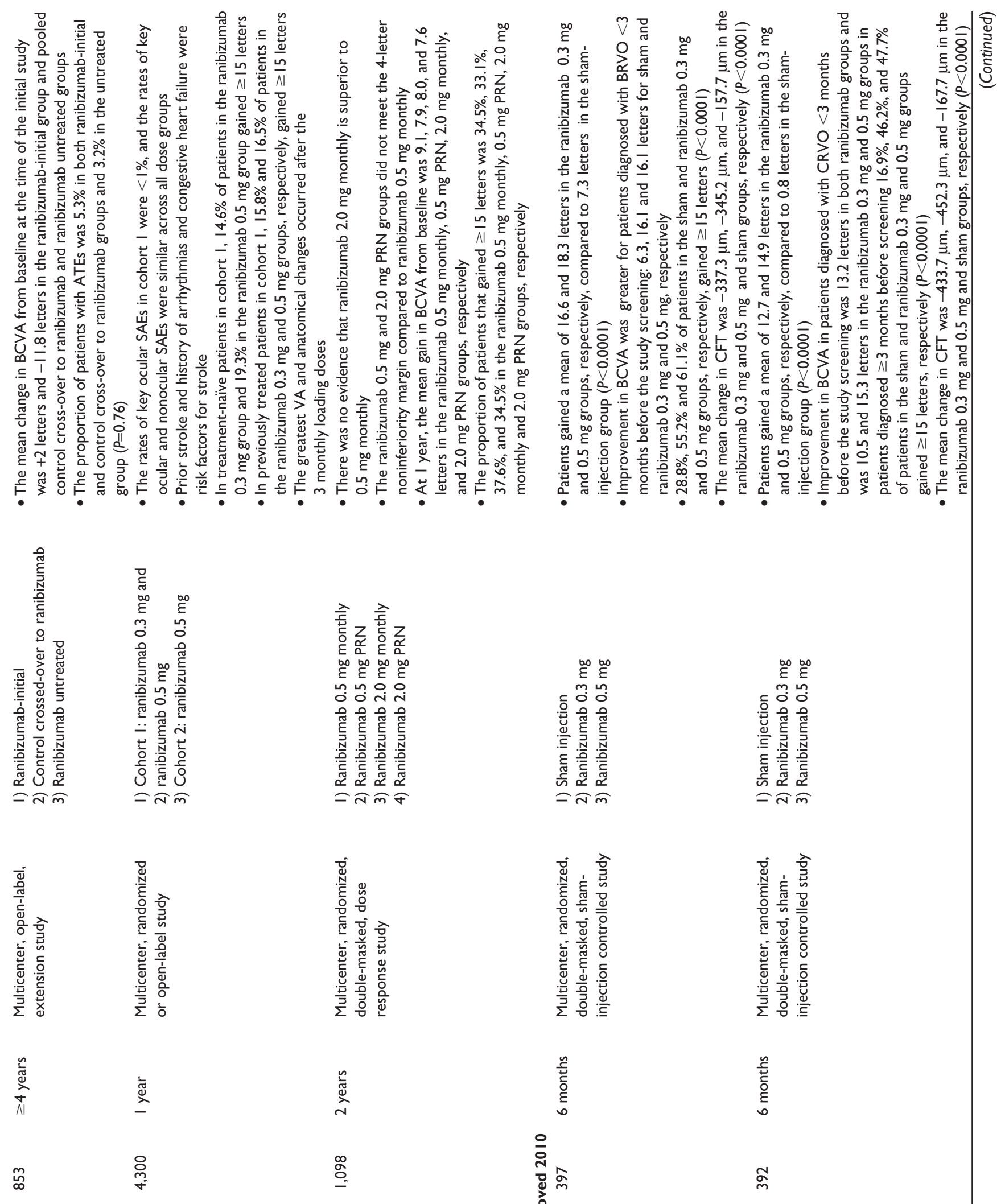

o̊

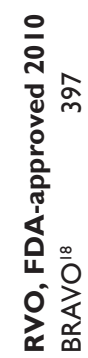

హ్

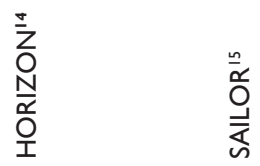

$\frac{1}{0}$
$\frac{1}{0}$
0
0
0
$\frac{1}{4}$
I

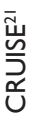




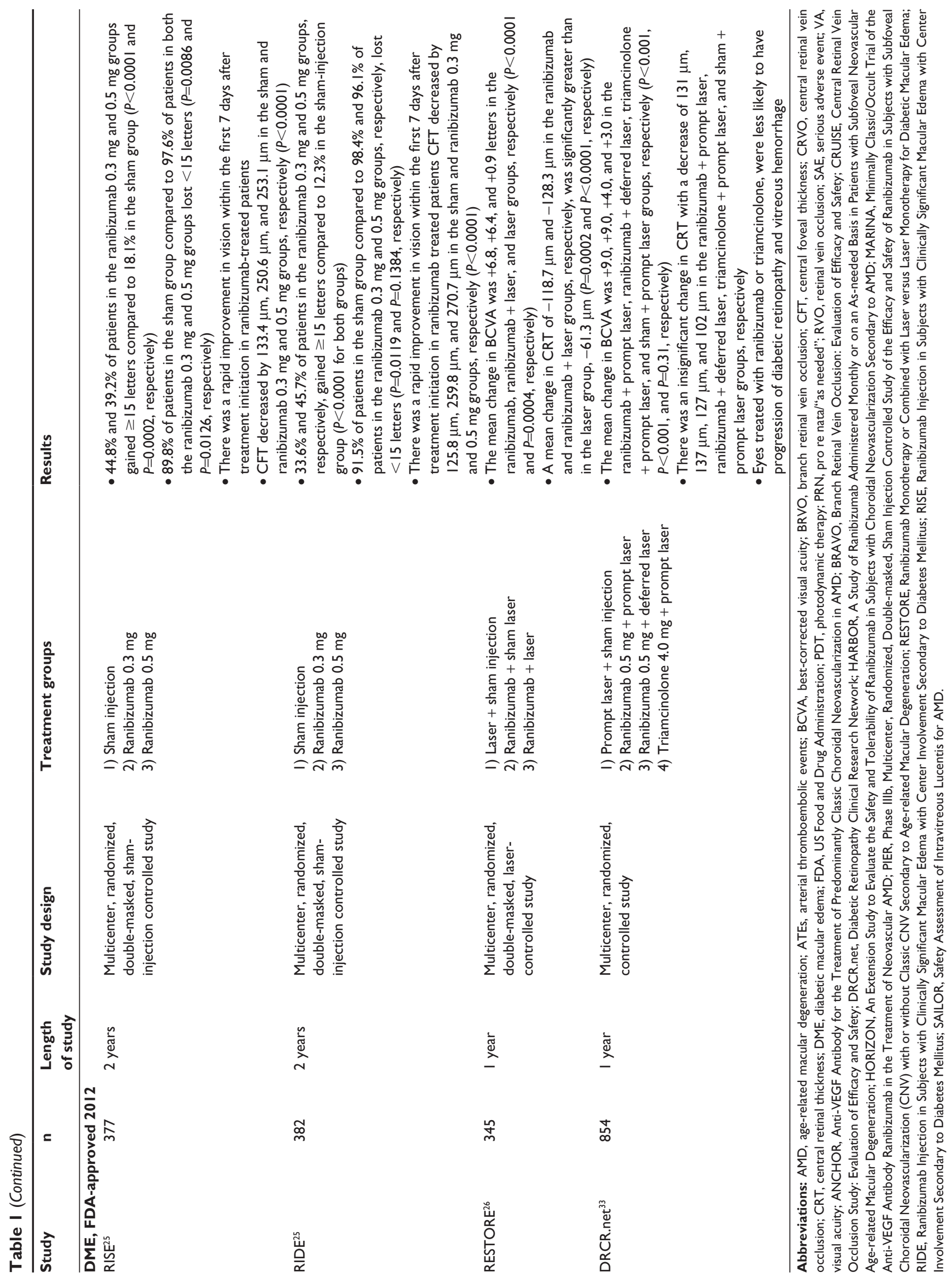


from quarterly to monthly dosing, suggesting that more frequent treatment might provide greater visual benefits. ${ }^{12,13}$ Therefore, not only did ranibizumab-treated patients have improved visual outcomes compared to sham-injection patients, but they also obtained greater benefit with more frequent treatment. ${ }^{12,13}$ The results of PIER ${ }^{12,13}$ also highlight the importance of early treatment, as patients in the shaminjection group that converted to ranibizumab $0.5 \mathrm{mg}$ after 1 year continued to experience visual decline during year 2 , with limited benefit from treatment. Similarly, the results from An Extension Study to Evaluate the Safety and Tolerability of Ranibizumab in Subjects with Choroidal Neovascularization Secondary to AMD (HORIZON) ${ }^{14}$ suggested that switching from a more frequent treatment regimen, adherent to a strict monthly schedule, to a less frequent, investigator-determined as-needed dosing, regimen (pro re nata [PRN]) led to worsening of disease with poorer visual outcomes.

More recently, the results from HARBOR ${ }^{16,17}$ suggested a slight increase in the durability of the higher dose of ranibizumab, as fewer injections were required in the ranibizumab $2.0 \mathrm{mg}$ PRN group versus the $0.5 \mathrm{mg}$ PRN group, although a greater effect on visual outcome was not concomitantly demonstrated. Furthermore, the variability in the injection frequency among the PRN dosing groups in HARBOR $^{16,17}$ (three to 24 injections over 2 years in the ranibizumab $0.5 \mathrm{mg}$ group) suggested that some patients were being overtreated or undertreated in the fixed dosing regimen. This is an important consideration when evaluating treatment burden and risk of adverse events (AEs), as an ideal treatment regimen maximizes outcome while minimizing the risk of developing serious AEs (SAEs), both ocular and nonocular.

With the presence and emergence of intravitreal antiVEGF agents other than ranibizumab, studies evaluating the efficacy of these medications have been, and are being, conducted. Such studies have reported similar visual gains in patients receiving ranibizumab versus bevacizumab (Avastin; Genentech, Inc./Roche) or aflibercept (Eylea; Regeneron, Tarrytown, NY, USA). In the Comparison of Age-related Macular Degeneration Treatments Trials (CATT), ${ }^{26,27}$ the ranibizumab $0.5 \mathrm{mg}$ PRN group had a gain of 6.7 letters in best-corrected visual acuity (BCVA) at 2 years with an average of 12.6 injections, while the bevacizumab $1.25 \mathrm{mg}$ PRN group had a gain of 5.0 letters with an average of 14.1 injections. In VEGF Trap-Eye: Investigation of Efficacy and Safety in Wet AMD (VIEW 1/2), ${ }^{28}$ the ranibizumab $0.5 \mathrm{mg}$ every 4 weeks (q4 $\mathrm{w}$ )/PRN group gained an average of 7.9 letters with 16.5 injections compared to 7.6 letters with 16.0 injections, 6.6 letters with 16.2 injections, and 7.6 letters with 11.2 injections in the aflibercept $2.0 \mathrm{mg} \mathrm{q} 4 \mathrm{w} / \mathrm{PRN}$, aflibercept $0.5 \mathrm{mg} \mathrm{q} 4 \mathrm{w} / \mathrm{PRN}$, and aflibercept $2.0 \mathrm{mg} \mathrm{q} 8 \mathrm{w} / \mathrm{PRN}$ groups, respectively. The results of these studies demonstrate noninferiority between ranibizumab and bevacizumab, and noninferiority between ranibizumab and aflibercept, as similar visual outcomes were seen.

The results from all these studies showed that treatment of neovascular AMD with intravitreal ranibizumab not only prevented the loss of vision, but also improved vision and that ranibizumab is an effective treatment modality for neovascular AMD with an acceptable safety profile. Additionally, benefits were noted with respect to all angiographic subtypes, minimally classic or occult lesions, ${ }^{9}$ as well as predominantly classic lesions. ${ }^{10,11}$

\section{RVO}

Ranibizumab was FDA-approved for the treatment of ME secondary to RVO in 2010, the same year that the BRAVO $^{18}$ and CRUISE ${ }^{21}$ study results, evaluating ranibizumab treatment of ME in BRVO and CRVO, were published. In BRAVO, ${ }^{18}$ patients treated with ranibizumab $0.3 \mathrm{mg}$ and $0.5 \mathrm{mg}$ gained an average of 16.6 and 18.3 letters, respectively, versus 7.3 letters in the sham-injection group $(P<0.0001)$. It was also noted that a rapid and dramatic improvement in patients treated with ranibizumab occurred in the initial 7 days following the first injection, with an average of 7.5 letters of improvement. ${ }^{18}$ The results from BRAVO $^{18}$ also found that the mean decrease in central foveal thickness (CFT) was significantly greater in both ranibizumab groups than in the sham-injection group $(P<0.0001)$, with a significantly greater excess foveal thickness in the sham-injection group $(P<0.0001)$. Upon further evaluation of the VA gains, vision $\geq 20 / 40$ was reported in $>65 \%$ of patients treated with ranibizumab by 6 months compared to $42 \%$ in the sham-injection group. ${ }^{18}$ Additionally, fewer patients in the ranibizumab treatment groups required rescue grid laser therapy after month 3 than in the sham-injection group: $18.7 \%(0.3 \mathrm{mg})$ and $19.8 \%(0.5 \mathrm{mg})$ versus $54.5 \%$ in the sham-injection group. The reports from the BRAVO ${ }^{19}$ study that was extended to 1 year found that VA gains were maintained with PRN treatment from months 7 through 12, but that the sham/ ranibizumab $0.5 \mathrm{mg}$ group (patients receiving sham injection for the first 6 months, followed by ranibizumab $0.5 \mathrm{mg}$ PRN for months 7 through 12) did not achieve VA gains as great as those in patients receiving ranibizumab during the first 6 months as well. 
Findings from the CRUISE ${ }^{21}$ trial also showed significantly greater improvements in BCVA and greater decreases in CFT in both ranibizumab-treated groups than sham $(P<0.0001$ for both factors). Additionally, patients treated with ranibizumab had lower excess foveal thickness than untreated patients. ${ }^{21}$ These findings were also maintained at 1 year. ${ }^{23}$ The Central Vein Occlusion Study $(\mathrm{CVOS})^{29}$ preceded CRUISE ${ }^{21}$ and evaluated macular grid photocoagulation for ME in CRVO. In $\mathrm{CVOS}^{29}$ and CRUISE, ${ }^{21}$ a similar percentage of patients with a presenting VA of $20 / 50$ to $20 / 200$ finished with VA $\geq 20 / 40,19 \%$ and $20.8 \%$, respectively. One difference between the two studies was that in CRUISE, ${ }^{21}$ there was a dramatic improvement in BCVA during the first 7 days after treatment, suggesting that treatment with intravitreal ranibizumab may promote faster recovery of vision.

In an extension trial for BRAVO ${ }^{18}$ and $\mathrm{CRUISE}^{21}$ (HORIZON), ${ }^{22}$ patients with BRVO had more stabilized gains with less frequent treatment, while patients with CRVO had decreasing visual outcomes with less frequent treatment. This HORIZON $^{22}$ study showed that many patients with BRVO and CRVO continued to require treatment with ranibizumab 2 years after treatment initiation and had poorer outcomes with less frequent follow-up. Additionally, the results of $\mathrm{HORIZON}^{22}$ showed that the group originally randomized to sham that crossed-over to ranibizumab $0.5 \mathrm{mg}$ (sham $/ 0.5 \mathrm{mg}$ ) and the groups randomized to ranibizumab from the start of BRAVO $^{18}(0.3 \mathrm{mg} / 0.5 \mathrm{mg}$ and $0.5 \mathrm{mg})$ had similar visual outcomes. Finally, in both BRAVO ${ }^{18}$ and CRUISE, ${ }^{21}$ intraretinal hemorrhages cleared more rapidly in the ranibizumab-treated groups. While the mechanism of effect is unclear, such findings may alter management. As hemorrhage impedes grid laser therapy, the presence of intraretinal hemorrhages for a shorter period of time may allow for earlier laser in patients requiring adjunctive therapy.

In another extension trial, Branch Retinal Vein Occlusion or Central Retinal Vein Occlusion Study (RETAIN), ${ }^{24}$ which included patients from BRAVO ${ }^{18}$ and CRUISE ${ }^{21}$ who finished HORIZON, ${ }^{22} 50 \%$ of patients with BRVO and $44 \%$ of patients with CRVO had resolution of edema without injection of ranibizumab for at least 6 months. Of these patients, approximately $80 \%$ with BRVO and $64 \%$ with CRVO had a $V A \geq 20 / 40$. In the patients who continued to require treatment with ranibizumab, $80 \%$ of patients with BRVO and $28 \%$ of patients with CRVO had VA $\geq 20 / 40 .{ }^{24}$

The data from the BRAVO, ${ }^{18}$ CRUISE, ${ }^{21}$ HORIZON,${ }^{22}$ and RETAIN ${ }^{24}$ studies demonstrate that intravitreal ranibizumab therapy is effective for the reduction of ME and improvement in VA. There was variation in the responses to therapy in patients with BRVO versus CRVO, with more pronounced effects in patients with BRVO. Although the reason for this is unknown, this may be secondary to the fact that patients with CRVO tend to have greater amounts of retinal ischemia than patients with BRVO.

\section{DME}

The treatment of DME with intravitreal ranibizumab was FDA-approved in 2012. The RISE and RIDE ${ }^{25}$ studies were two parallel studies in patients with vision loss from DME. In the RISE and RIDE $^{25}$ studies patients treated with ranibizumab $0.3 \mathrm{mg}$ and $0.5 \mathrm{mg}$ had significant improvement in VA with more patients losing < 15 letters when compared to sham. In RISE, ${ }^{25} 44.8 \%$ and $39.2 \%$ of patients in the ranibizumab $0.3 \mathrm{mg}$ and $0.5 \mathrm{mg}$ groups, respectively, gained $\geq 15$ letters compared to $18.1 \%$ in the sham-injection group ( $P<0.0001$ and $P=0.0002$, respectively). Similar findings were also reported in RIDE. ${ }^{25}$ Notably, in RIDE, ${ }^{25}$ the proportion of patients losing $<15$ letters was not significantly different between sham injection and ranibizumab $0.5 \mathrm{mg}$ patients $(P=0.1384)$. The greatest improvement in VA was seen within 7 days of the first injection of ranibizumab in both RIDE and RISE. ${ }^{25}$ Both studies also reported a significant improvement in CFT in patients treated with ranibizumab compared to sham injection $(P<0.0001)$, starting at day 7 and maintained to the end of the study. ${ }^{25}$ These results show that intravitreal ranibizumab treatment may reverse vision loss from DME.

The long-term outcomes of the RISE and $\operatorname{RIDE}^{30}$ studies showed that the VA gains and anatomical improvement seen in the first 2 years was maintained through the third year. Similar to the data reported in patients with ME after RVO, delayed treatment with ranibizumab did result in VA gains, although these gains were not as extensive as those seen in patients receiving treatment from day $0 .{ }^{30}$

In the Ranibizumab Monotherapy or Combined with Laser versus Laser Monotherapy for Diabetic Macular Edema (RESTORE) ${ }^{31}$ study, there were significantly greater improvements in BCVA in patients treated with ranibizumab and ranibizumab + laser than in patients treated with laser alone $(P<0.0001)$, and no significant difference was found between the ranibizumab and ranibizumab + laser groups from baseline to month 1 through month $12(P=0.61)$. Both ranibizumab groups also experienced significant improvement in central retinal thickness (CRT) than the laser group. The RESTORE ${ }^{31}$ study showed that treatment with ranibizumab, whether alone or in combination with laser therapy, 
was superior to laser treatment. This study also evaluated health-related quality of life, reporting progressive and sustained improvements in quality of life in patients treated with ranibizumab. ${ }^{31}$ Such benefits of ranibizumab therapy were seen in general vision and in near and distance activities. ${ }^{31}$ Subgroup analysis of data from RESTORE ${ }^{31}$ showed that BCVA improvements with ranibizumab, compared to laser, were greatest for patients with CRT $>400 \mu \mathrm{m}$. This finding played a critical role in the National Institute for Health and Care Excellence approval of ranibizumab only for eyes with CRT $>400 \mu \mathrm{m}$. Data from an extension of the RESTORE ${ }^{32}$ study showed that the improvements in BCVA and CRT were maintained at year 3 , with patients requiring progressively fewer injections over this time.

The Diabetic Retinopathy Clinical Research Network (DRCR.net) ${ }^{33}$ study was performed in patients with decreasedVA and fovea-involving DME. Five-year results from DRCR.net ${ }^{34}$ showed that patients treated with ranibizumab + prompt laser and ranibizumab + deferred laser maintained visual gains from years 1 through 5, requiring less frequent treatment after year 3. Additionally, while prompt laser treatment was not better than deferred laser treatment, patients in whom laser treatment was deferred required more injections of ranibizumab. ${ }^{34}$

Improvement in both VA and retinal thickening in patients with diabetes treated with ranibizumab supports the use of this medication for treating vision loss from DME. Other findings noted in some of the above studies suggest that patients treated with ranibizumab may not only be less likely to have progression of DR, but also have improvement in the severity of DR. Thus, visual morbidity could potentially be avoided with prompt treatment with ranibizumab. Although many patients in the aforementioned studies required continuous ranibizumab treatment, some reported that with time, progressively fewer injections were required to maintain treatment effect.

\section{Safety}

Numerous trials examining the efficacy and safety of intravitreal anti-VEGF therapies have showed that, while frequent injections of anti-VEGF agents greatly reduce the risk of vision loss in patients with posterior segment neovascularization, these medications can also be associated with ocular and nonocular AEs and SAEs. In MARINA, ${ }^{9}$ presumed endophthalmitis, uveitis, rhegmatogenous retinal detachment, retinal tear, vitreous hemorrhage, and lens damage were reported with an incidence varying from $0 \%$ to $1.3 \%$ in treated groups. Additionally, rhegmatogenous retinal detachment and vitreous detachment were reported in $0.4 \%$ and $0.8 \%$ of patients, respectively, in the sham group. ${ }^{9}$ In some patients, sterile uveitis was not distinguished definitively from endophthalmitis, and treatment with intravitreal antibiotics in a culture-negative patient was reported as endophthalmitis. An endophthalmitis rate of $1.0 \%$ or $0.05 \%$ per injection was reported in MARINA, ${ }^{9}$ and similar rates were also reported in ranibizumab-treated patients with RVO and DME. ${ }^{18,22,25}$ No endophthalmitis or serious intraocular inflammation was reported in PIER, ${ }^{12,13}$ and the AEs that occurred more frequently in treated groups were those commonly associated with intravitreal injections.

Ocular SAEs occurred in $<4.0 \%$ of patients across all treatment groups in HARBOR, ${ }^{16,17}$ and nonocular SAEs were well balanced among all treatment groups without a dose-response trend. No ocular SAEs were reported in the ranibizumab group in the RESTORE ${ }^{31}$ study, although two cases were reported in each of the other two groups, ranibizumab + laser and laser. SAILOR ${ }^{15}$ is the largest study to evaluate the safety as a primary end point of intravitreal ranibizumab in neovascular AMD patients. Results from SAILOR $^{15}$ demonstrated that ranibizumab was well tolerated, with a low, dose-independent incidence of ocular AEs and SAEs.

A growing concern with intravitreal ranibizumab use is the possibility of increased risk of occurrence and increased growth rate of geographic atrophy in patients with AMD. Regarding the risk of developing geographic atrophy in the CATT trial, ranibizumab compared with bevacizumab had a higher risk (adjusted hazard ratio [aHR], 1.43; 95\% confidence interval [CI], 1.06-1.93), and monthly dosing had a higher risk (aHR, 1.59; 95\% CI, 1.17-2.16) than PRN dosing. ${ }^{35}$ Data also suggests that geographic atrophy expands at a faster rate in patients treated with ranibizumab. The CATT trial reported a growth rate of $0.37 \mathrm{~mm} /$ year in eyes treated with bevacizumab and of $0.49 \mathrm{~mm} /$ year in eyes treated with ranibizumab $(P=0.03) .{ }^{36}$ Results showed no significant difference in the growth rate of geographic atrophy in patients treated monthly versus PRN $(P=0.85){ }^{36}$

Nonocular SAEs (myocardial infarction, stroke, and death) were reported in $0.8 \%$ to $2.5 \%$ of patients in control and treatment groups in MARINA. ${ }^{9}$ In ANCHOR, ${ }^{10,11}$ a slightly higher rate of nonocular hemorrhage and thromboembolic events was seen in ranibizumab-treated patients, although this was not found to be significant. Cerebrovascular accidents (CVA) occurred in $1.6 \%$ of patients in the sham groups and in $0.8 \%$ of patients in the ranibizumab $0.3 \mathrm{mg}$ groups in RISE and $\mathrm{RIDE}^{25}$ and in $4.0 \%$ in the ranibizumab 
$0.5 \mathrm{mg}$ group in RISE and 2.4\% in the ranibizumab $0.5 \mathrm{mg}$ group in RIDE. ${ }^{25}$ While a higher rate of strokes was seen in the higher-dose group (insignificant) in SAILOR, ${ }^{15}$ there was no difference between the dose groups in the rate of Antiplatelet Trialists' Collaboration (APTC) arterial thromboembolic events. The incidence of APTC thromboembolic events in $\mathrm{BRAVO}^{18}$ was low, also without a significant difference between the treatment and control groups. Arterial thromboembolic events defined by the APTC criteria were balanced among all groups, sham and ranibizumab, in the CRUISE trial. ${ }^{22}$ Finally, in the DRCR.net ${ }^{33}$ study, patients treated with prompt laser had similar rates of major ocular AEs and APTC cardiovascular events as patients receiving ranibizumab.

While most studies reported on AEs and the rates of these events among different groups, these studies were not powered to detect small differences in the rates of infrequent events. Overall, intravitreal treatment with ranibizumab was well tolerated, with low rates of AEs.

\section{Cost}

With the rising costs of health care and the limited budgets, there is increasingly more data assessing the cost burden associated with intravitreal anti-VEGF treatment. Additionally, patients are not only burdened by frequent treatment, often monthly, but they are also burdened with frequent visits for evaluation and monitoring. For these reasons, some studies have assessed the cost-effectiveness of different treatment regimens and others have attempted to reduce patient visits and treatment frequency. Dankin et $\mathrm{al}^{37}$ reported that ranibizumab is not cost-effective when compared to bevacizumab for the treatment of neovascular AMD, with 2 year cost for continuous ranibizumab approximately five times the cost for continuous bevacizumab and no difference in qualityadjusted life-years gained. Similarly, Stein et $\mathrm{al}^{38}$ reported that ranibizumab PRN was more costly and less effective than continuous bevacizumab, with 20 year costs of $\$ 257,496$, $\$ 163,694, \$ 79,771$, and $\$ 65,267$ for ranibizumab monthly, ranibizumab PRN, bevacizumab monthly, and bevacizumab PRN, respectively. The data from this study showed that bevacizumab conferred greater value than ranibizumab for the treatment of neovascular AMD. ${ }^{38}$ Bevacizumab is used off-label for the treatment of neovascular AMD, DME, proliferative DR, RVO, and non-AMD causes of CNV, and its use will likely continue as there is a significant difference in cost without a similar difference in efficacy when compared to FDA-approved treatments, such as ranibizumab, in studies performed to date.

\section{Conclusion}

Intravitreal ranibizumab is a safe and effective treatment for neovascular AMD, RVO, and DME. It can successfully reverse vision loss in patients with these conditions and is well tolerated. The visual and anatomic improvements seen with ranibizumab can hopefully allow patients to maintain their quality of life and prevent severe vision loss.

Assessment of the data within individual studies and comparison between studies can be limited by multiple factors. In SAILOR, ${ }^{15}$ there may have been a lack of interinvestigator consistency in assessment of fluorescein angiography, as different investigators made inclusion and exclusion assessments based on fluorescein angiography findings. Additionally, a large proportion of patients discontinued the study early. This was also seen in other studies, especially those with longer-term follow-up. For example, in the RIDE and RISE $^{30}$ studies, $20 \%$ to $32.2 \%$ of patients did not complete the study to 3 years. Selection bias may also play a role, as some studies may have been more likely to enroll patients with more severe or treatment-refractory disease while others enrolled patients with less severe disease. Also, in studies requiring investigators to determine need for PRN ranibizumab treatment or laser treatment, there is the potential for significant variability. The HORIZON ${ }^{22}$ study for RVO was limited as it was an open-label, nonrandomized trial. In addition, interstudy comparison may not be possible due to variability in inclusion and exclusion criteria. Patients with stroke and transient ischemic attack were excluded from RESTORE $^{31}$ and CRUISE, ${ }^{21}$ which only included patients with BCVA $<20 / 40$, potentially excluding patients with less severe disease. The applicability of the results of the HARBOR ${ }^{16,17}$ study may be limited as the studied population was a fairly homogeneous population within the United States only. Finally, interstudy comparison may not be possible due to differences inherent to the studies. The use of triamcinolone in DRCR.net ${ }^{33}$ likely led to the more rapid development of cataracts in treated patients, confounding visual outcomes.

While the benefit from ranibizumab treatment is tremendous, and the treatment regimen is well tolerated, many important questions remain unanswered. In patients with ME due to RVO, it remains unclear when treatment should be initiated, as a small percentage of patients improve spontaneously ${ }^{29,39}$ and may be unnecessarily exposed to risk with treatment. On the other hand, many studies showed the greatest treatment effect within the first 7 days of treatment and with earlier initiation of ranibizumab therapy. The role of adjunctive therapy is also unclear and further studies are necessary. 
As the safety of intravitreal ranibizumab is evaluated, it is important to consider that some ocular AEs and SAEs are inherent to all intravitreal injections, not just ranibizumab. Additionally, certain nonocular AEs and SAEs are more common in the diseased population in general, not specific to those receiving ranibizumab. For example, the incidence of death and CVA were higher in the ranibizumab groups in RISE and RIDE, ${ }^{25}$ although it is known that patients with diabetes and DME are already at a greater risk of myocardial infarction and CVA compared to patients with diabetes without ophthalmic complications. ${ }^{40}$ Additionally, some studies showed the reverse effect, with higher rates of AEs in control patients. The results from DRCR.net ${ }^{33}$ showed that shamtreated patients had higher rates of vascular death, myocardial infarction, and CVA than ranibizumab-treated patients.

Ranibizumab for the treatment of neovascular AMD, ME in RVO, and DME is effective and safe. It has greatly expanded the available armamentarium of FDA-approved treatments for the aforementioned conditions and has been shown, time and time again, to improve vision and prevent further vision loss in patients with neovascular posterior segment diseases.

\section{Acknowledgment}

This study was supported by Research to Prevent Blindness, New York, NY, USA.

\section{Disclosure}

The authors report no conflicts of interest in this work.

\section{References}

1. Grisanti S, Tatar O. The role of vascular endothelial growth factor and other endogenous interplayers in age-related macular degeneration. Prog Retin Eye Res. 2008;27(4):372-390.

2. Kvanta A, Algvere PV, Berglin L, Seregard S. Subfoveal fibrovascular membranes in age-related macular degeneration express vascular endothelial growth factor. Invest Ophthalmol Vis Sci. 1996; 37(9):1929-1934.

3. Adamis AP, Aiello LP, D'Amato RA. Angiogenesis and ophthalmic disease. Angiogenesis. 1999;3(1):9-14.

4. Adamis AP, Shima DT. The role of vascular endothelial growth factor in ocular health and disease. Retina. 2005;25(2):111-118.

5. Seddon JM, Chen CA. The epidemiology of age-related macular degeneration. Int Ophthalmol Clin. 2004;44(4):17-39.

6. Bressler NM. Age-related macular degeneration is the leading cause of blindness. JAMA. 2004;291(15):1900-1901.

7. Saeed MU, Gkaragkani E, Ali K. Emerging roles for antiangiogenesis factors in management of ocular disease. Clin Ophthalmol. 2013;6:533-543.

8. Veritti D, Sarao V, Lanzetta P. Neovascular age-related macular degeneration. Ophthalmologica. 2012;227(Suppl 1):11-20.

9. Rosenfeld PJ, Brown DM, Heier JS, et al; MARINA Study Group. Ranibizumab for neovascular age-related macular degeneration. $N$ Engl J Med. 2006;355(14):1419-1431.

10. Brown DM, Kaiser PK, Michels M, et al; ANCHOR Study Group. Ranibizumab versus verteporfin for neovascular age-related macular degeneration. $N$ Engl J Med. 2006;355(14):1432-1444.
11. Brown DM, Michels M, Kaiser PK, Heier JS, Sy JP, Ianchulev T; ANCHOR Study Group. Ranibizumab versus verteporfin photodynamic therapy for neovascular age-related macular degeneration: two-year results of the ANCHOR study. Ophthalmology. 2009;116(1): 57-65.e5.

12. Regillo CD, Brown DM, Abraham P, et al. Randomized, doublemasked, sham-controlled trial of ranibizumab for neovascular agerelated macular degeneration: PIER Study year 1. Am J Ophthalmol. 2008;145(2):239-248.

13. Abraham $P$, Yue H, Wilson L. Randomized, double-masked, sham-controlled trial of ranibizumab for neovascular age-related macular degeneration: PIER study year 2. Am J Ophthalmol. 2010;150(3):315-324.e1.

14. Singer MA, Awh CC, Sadda S, et al. HORIZON: an open-label extension trial of ranibizumab for choroidal neovascularization secondary to age-related macular degeneration. Ophthalmology. 2012;119(6):1175-1183.

15. Boyer DS, Heier JS, Brown DM, Francom SF, Ianchulev T, Rubio RG. A Phase IIIb study to evaluate the safety of ranibizumab in subjects with neovascular age-related macular degeneration. Ophthalmology. 2009;116(9):1731-1739.

16. Busbee BG, Ho AC, Brown DM, et al; HARBOR Study Group. Twelve-month efficacy and safety of $0.5 \mathrm{mg}$ or $2.0 \mathrm{mg}$ ranibizumab in patients with subfoveal neovascular age-related macular degeneration. Ophthalmology. 2013;120(5):1046-1056.

17. Ho AC, Busbee BG, Regillo CD, et al; HARBOR Study Group. Twentyfour-month efficacy and safety of $0.5 \mathrm{mg}$ or $2.0 \mathrm{mg}$ ranibizumab in patients with subfoveal neovascular age-related macular degeneration. Ophthalmology. 2014;121(11):2181-2192.

18. Campochiaro PA, Heier JS, Feiner L, et al; BRAVO Investigators. Ranibizumab for macular edema following branch retinal vein occlusion: six-month primary end point results of a phase III study. Ophthalmology. 2010;117(6):1102-1112.e1.

19. Brown DM, Campochiaro PA, Bhisitkul RB, et al. Sustained benefits from ranibizumab for macular edema following branch retinal vein occlusion: 12-month outcomes of a phase III study. Ophthalmology. 2011;118(8):1594-1602.

20. Varma R, Bressler NM, Suñer I, et al; BRAVO and CRUISE Study Groups. Improved vision-related function after ranibizumab for macular edema after retinal vein occlusion: results from the BRAVO and CRUISE trials. Ophthalmology. 2012;119(10):2108-2118.

21. Brown DM, Campochiaro PA, Singh RP, et al; CRUISE Investigators. Ranibizumab for macular edema following central retinal vein occlusion: six-month primary end point results of a phase III study. Ophthalmology. 2010;117(6):1124-1133.e1.

22. Heier JS, Campochiaro PA, Yau L, et al. Ranibizumab for macular edema due to retinal vein occlusions: long-term follow-up in the HORIZON trial. Ophthalmology. 2012;119(4):802-809.

23. Campochiaro PA, Brown DM, Awh CC, et al. Sustained benefits from ranibizumab for macular edema following central retinal vein occlusion: twelve-month outcomes of a phase III study. Ophthalmology. 2011;118(10):2041-2049.

24. Campochiaro PA, Sophie R, Pearlman J, et al; RETAIN Study Group. Long-term outcomes in patients with retinal vein occlusion treated with ranibizumab: the RETAIN study. Ophthalmology. 2014;121(1):209-219.

25. Nguyen QD, Brown DM, Marcus DM, et al; RISE and RIDE Research Group. Ranibizumab for diabetic macular edema: results from 2 phase III randomized trials: RISE and RIDE. Ophthalmology. 2012;119(4):789-801.

26. Martin DF, Maguire MG, Ying GS, Grunwald JE, Fine SL, Jaffe GJ; CATT Research Group. Ranibizumab and bevacizumab for neovascular age-related macular degeneration. $N$ Engl $J$ Med. 2011;364(20):1897-1908

27. Martin DF, Maguire MG, Fine SL, et al; Comparison of Age-related Macular Degeneration Treatments Trials (CATT) Research Group. Ranibizumab and bevacizumab for treatment of neovascular agerelated macular degeneration: two-year results. Ophthalmology. 2012;119(7):1388-1398. 
28. Heier JS, Brown DM, Chong V, et al; VIEW 1 and VIEW 2 Study Groups. Intravitreal aflibercept (VEGF trap-eye) in wet age-related macular degeneration. Ophthalmology. 2012;119(12):2537-2548.

29. Evaluation of grid pattern photocoagulation for macular edema in central vein occlusion. The Central Vein Occlusion Study Group M report. Ophthalmology. 1995;102(10):1425-1433.

30. Brown DM, Nguyen QD, Marcus DM, et al; RIDE and RISE Research Group. Long-term outcomes of ranibizumab therapy for diabetic macular edema: the 36-month results from two phase III trials: RISE and RIDE. Ophthalmology. 2013;120(10):2013-2022.

31. Mitchell P, Bandello F, Schmidt-Erfurth U, et al; RESTORE study group. The RESTORE study: ranibizumab monotherapy or combined with laser versus laser monotherapy for diabetic macular edema. Ophthalmology. 2011;118(4):615-625.

32. Schmidt-Erfurth U, Lang GE, Holz FG, et al; RESTORE Extension Study Group. Three-year outcomes of individualized ranibizumab treatment in patients with diabetic macular edema: the RESTORE extension study. Ophthalmology. 2014;121(5):1045-1053.

33. Elman MJ, Aiello LP, Beck RW, et al; Diabetic Retinopathy Clinical Research Network. Randomized trial evaluating ranibizumab plus prompt or deferred laser or triamcinolone plus prompt laser for diabetic macular edema. Ophthalmology. 2010;117(6):1064-1077.e35.

34. Elman MJ, Ayala A, Bressler NM; Diabetic Retinopathy Clinical Research Network. Intravitreal ranibizumab for diabetic macular edema with prompt versus deferred laser treatment: 5-year randomized trial results. Ophthalmology. Epub 2014 Oct 28.
35. Grunwald JE, Daniel E, Huang J, et al; CATT Research Group. Risk of geographic atrophy in the comparison of age-related macular degeneration treatments trials. Ophthalmology. 2014;121(1):150-161.

36. Grunwald JE, Pistilli M, Ying G, et al. Growth of geographic atrophy in the comparison of age-related macular degeneration treatments trials. Ophthalmology. Epub 2014 Dec 24.

37. Dankin HA, Wordsworth S, Rogers CA, et al; IVAN Study Investigators. Cost-effectiveness of ranibizumab and bevacizumab for age-related macular degeneration: 2-year findings from the IVAN randomised trial. BMJ Open. 2014;4(7):e005094.

38. Stein JD, Newman-Casey PA, Mrinalini T, Lee PP, Hutton DW. Cost-effectiveness of bevacizumab and ranibizumab for newly diagnosed neovascular macular degeneration. Ophthalmology. 2014;121(4):936-945.

39. Argon laser photocoagulation for macular edema in branch retinal vein occlusion. The Branch Vein Occlusion Study Group. Am JOphthalmol. 1984;98(3):271-282.

40. Hirai FE, Knudtson MD, Klein BE, Klein R. Clinically significant macular edema and survival in type 1 and type 2 diabetes. Am J Ophthalmol. 2008;145(4):700-706.
Clinical Ophthalmology

\section{Publish your work in this journal}

Clinical Ophthalmology is an international, peer-reviewed journal covering all subspecialties within ophthalmology. Key topics include: Optometry; Visual science; Pharmacology and drug therapy in eye diseases; Basic Sciences; Primary and Secondary eye care; Patient Safety and Quality of Care Improvements. This journal is indexed on

\footnotetext{
Submit your manuscript here: http://www.dovepress.com/clinical-ophthalmology-journal
}

\section{Dovepress}

PubMed Central and CAS, and is the official journal of The Society of Clinical Ophthalmology (SCO). The manuscript management system is completely online and includes a very quick and fair peer-review system, which is all easy to use. Visit http://www.dovepress.com/ testimonials.php to read real quotes from published authors. 